\title{
Microphase-Separation Behavior of Triblock Copolymer Melts. Comparison with Diblock Copolymer Melts
}

\author{
Shao-Min Mai, ,,† Withawat Mingvanish, ${ }^{\dagger}$ Simon C. Turner, ${ }^{\ddagger}$ \\ Chiraphon Chaibundit, ${ }^{\dagger}$ J . Patrick A. Fairclough, ${ }^{\dagger}$ Frank Heatley, ${ }^{\dagger}$ \\ Mark W. Matsen,,$^{\S}$ Anthony J . Ryan, ${ }^{\ddagger}$ and Colin Booth ${ }^{\dagger}$
}

Manchester Polymer Centre and Department of Chemistry, University of Manchester, Manchester M 13 9PL, UK, Department of Chemistry, University of Sheffield, Sheffield S3 7HF, UK, and Polymer Science Centre, University of Reading, Whiteknights, Reading RG6 6AF, UK

Received J anuary 28, 2000; Revised Manuscript Received April 25, 2000

\begin{abstract}
Nineteen oxybutylene/oxyethylene/oxybutylene triblock copolymers $\left[B_{n / 2} E_{m} B_{n / 2}, E=\right.$ oxyethylene, $\mathrm{OCH}_{2} \mathrm{CH}_{2} ; \mathrm{B}=$ oxybutylene, $\mathrm{OCH}_{2} \mathrm{CH}\left(\mathrm{CH}_{2} \mathrm{CH}_{3}\right)$ ] were prepared and characterized. Twelve of the copolymers microphase-separated in the melt. I nvestigation of this microphase-separation behavior using small-angleX-ray scattering (SAXS) yiel ded values of the domain spacing (d-spacings) in the ordered phases and of the temperature of the order-disorder transition ( $\left.T_{\mathrm{ODT}}\right)$. In several cases the ordered phase structure was deduced from a combination of 1D and 2D SAXS and rheology. Values of TODT for the triblock copolymers were ca. $100{ }^{\circ} \mathrm{C}$ lower than those for $\mathrm{E}_{m} \mathrm{~B}_{\mathrm{n}}$ diblock copolymers of identical composition and chain length but $30^{\circ} \mathrm{C}$ higher if compared with diblock copolymers of half the triblock length. Values of the d-spacings indicated that the triblock copolymers were 10\% more stretched than corresponding diblock copolymers. Determination of the Flory-Huggins parameter $(\chi)$ for the diblock and triblock systems gave identical results. The experimental results are compared with the prediction of mean-field theory.
\end{abstract}

\section{Introduction}

It is well-known that a change in molecular architecture at constant chain length and composition dramatically influences mi orophase separation, and hence physical properties, in block copolymer melts. ${ }^{1}$ Considering this microphase separation, the need to locate the two block-junctions of a triblock copolymer at a domain boundary significantly reduces the conformational entropy of its ordered state relative to that of a diblock copolymer of comparable composition and chain length. As a consequence, the disordered phase of a triblock copolymer melt is more stable than that of a diblock copolymer of the same length and composition. For the purposes of theory, the effect is described more precisely if comparison is made between the melt of a symmetric triblock copolymer and that of a hypothetical melt formed by snipping the triblock copolymer in half. It is then clear that pulling the middle block of the triblock copolymer out of its domain costs approximately twice as much Gibbs energy as pulling the block of one of the diblock copolymers from its domain, ${ }^{2}$ so that the melt of the triblock copolymer (now twice the length of the diblock) will remain ordered up to a higher temperature. Furthermore, theory predicts that, near to the orderdisorder transition (ODT), the additional segregation will amplify chain stretching and produce a larger domain spacing in the ordered triblock melt. ${ }^{3-5}$

The microphase-separation behavior of triblock copolymer melts near to the ODT has been investigated theoretically by Mayes and Olvera de la $\mathrm{Cruz}^{6,7}$ and Matsen and co-workers ${ }^{3-5}$ and experimentally by several groups. ${ }^{8-15}$ The experimental studies broadly confirm theory, but they were not intended to provide a

† University of Manchester.

₹ University of Sheffield.

$\S$ University of Reading.

* To whom correspondence should be addressed. detailed test covering both the ODT and the structural parameters of well-ordered microphases for a single copolymer system. The work reported here covers a range of triblock copolymers and allows cl ose comparison with the behavior of a corresponding series of dibl ock copolymers, thus going some way toward filling the gap.

A quantity of major importance in determining the ODT is the product $\left(\alpha r_{v}\right)$ of the Flory-Huggins parameter $(\chi)$ and the length $\left(r_{v}\right)$ of the copolymer chain defined by the number of segments of given reference volume. Mayes and Olvera de la Cruz showed 6 that the critical value for microphase separation of $\left(\chi r_{v}\right)_{c} \approx 18$ for the melt of a triblock copolymer with equal volume fractions of its two components compared to Leibler's value of $\left(\chi r_{v}\right)_{c} \approx 10.5$ for the melt of a diblock copolymer of the same length and composition. ${ }^{16}$

The phase diagram obtained was found to be asymmetric with respect to copolymer composition. As explained by Mayes and Olvera de la Cruz, ${ }^{6}$ this is an entropic effect. Consider two copolymer melts with hexagonal structure placed symmetrically on the phase diagram, e.g., volume fractions of the end-block component of $\phi=0.4$ and $\phi=0.6$. The stability of the ordered structure depends on whether the two end blocks are confined to the discontinuous phase $(\phi=0.4$, low entropy, least stable) or to the continuous phase ( $\phi=$ 0.6 , most stable).

The different effects of concentration fluctuations in the two systems were also considered. ${ }^{7}$ As for diblock copolymers, fluctuations in the disordered melt were found to cause an increase in $\left(\chi r_{v}\right)_{c}$. Considering diblock and triblock copolymers of the same chain length and composition, in the disordered triblock melt the interactions between one end block and the center block are coupled to those involving the other end block, so the fluctuation effect should be bigger. However, the fluc- 
Table 1. Molecular Characteristics and Microphase-Separation Behavior of $B_{n / 2} E_{m} B_{n / 2}$ Copolymers

\begin{tabular}{|c|c|c|c|c|c|c|c|c|c|}
\hline copolymer & $\mathrm{M}_{\mathrm{n}} / \mathrm{g} \mathrm{mol}^{-1}$ & $r_{v}^{a}$ & $r_{v} * a$ & $\phi_{\mathrm{B}}{ }^{\mathrm{a}}$ & $\begin{array}{c}d / \AA^{\mathrm{b}} \\
\left(70^{\circ} \mathrm{C}\right)\end{array}$ & $\begin{array}{c}\mathrm{T}_{\mathrm{ODT}} /{ }^{\circ} \mathrm{C}^{\mathrm{C}} \\
\text { SAXS }\end{array}$ & $\begin{array}{c}\mathrm{T}_{\mathrm{DOT}} /{ }^{\circ} \mathrm{C}^{\mathrm{e}} \\
\text { SAXS }\end{array}$ & $\begin{array}{l}\mathrm{T}_{\mathrm{ODT}} /{ }^{\circ} \mathrm{C}^{\mathrm{C}} \\
\text { rheology }\end{array}$ & $\begin{array}{l}\text { structure }^{d} \\
\left(70^{\circ} \mathrm{C}\right)\end{array}$ \\
\hline $\mathrm{B}_{17} \mathrm{E}_{201} \mathrm{~B}_{17}$ & 11300 & 265 & 133 & 0.242 & & & & & dis \\
\hline $\mathrm{B}_{20} \mathrm{E}_{141} \mathrm{~B}_{20}$ & 9100 & 217 & 108 & 0.349 & & & & & dis \\
\hline $\mathrm{B}_{28} \mathrm{E}_{182} \mathrm{~B}_{28}$ & 12000 & 288 & 144 & 0.368 & 115 & 83 & 83 & 85 & lam \\
\hline $\mathrm{B}_{25} \mathrm{E}_{143} \mathrm{~B}_{25}$ & 9900 & 237 & 119 & 0.398 & 107 & 89 & 87 & & Iam \\
\hline $\mathrm{B}_{11} \mathrm{E}_{47} \mathrm{~B}_{11}$ & 3700 & 89 & 44 & 0.469 & & & & & dis \\
\hline $\mathrm{B}_{30} \mathrm{E}_{122} \mathrm{~B}_{30}$ & 9700 & 235 & 118 & 0.482 & 105 & 102 & 99 & & Iam \\
\hline $\mathrm{B}_{37} \mathrm{E}_{150} \mathrm{~B}_{37}$ & 11900 & 290 & 145 & 0.483 & 121 & 143 & 142 & & Iam \\
\hline $\mathrm{B}_{14} \mathrm{E}_{56} \mathrm{~B}_{14}$ & 4500 & 109 & 55 & 0.486 & & & & & dis \\
\hline $\mathrm{B}_{27} \mathrm{E}_{105} \mathrm{~B}_{27}$ & 8500 & 207 & 104 & 0.493 & 99 & 84 & 82 & & Iam \\
\hline $\mathrm{B}_{29} \mathrm{E}_{111} \mathrm{~B}_{29}$ & 9100 & 221 & 110 & 0.497 & 100 & 92 & 88 & 92 & Iam \\
\hline $\mathrm{B}_{36} \mathrm{E}_{137} \mathrm{~B}_{36}$ & 11200 & 273 & 137 & 0.498 & 114 & 135 & 133 & 132 & Iam \\
\hline $\mathrm{B}_{26} \mathrm{E}_{95} \mathrm{~B}_{26}$ & 7900 & 193 & 97 & 0.508 & 93 & 68 & 67 & 71 & Iam \\
\hline $\mathrm{B}_{25} \mathrm{E}_{90} \mathrm{~B}_{25}$ & 7600 & 184 & 92 & 0.512 & $91\left(40^{\circ} \mathrm{C}\right)^{\mathrm{e}}$ & & 50 & & $\operatorname{lam}\left(40^{\circ} \mathrm{C}\right)^{\mathrm{e}}$ \\
\hline $\mathrm{B}_{20} \mathrm{E}_{70} \mathrm{~B}_{20}$ & 6000 & 146 & 73 & 0.519 & & & & & dis \\
\hline $\mathrm{B}_{24} \mathrm{E}_{79} \mathrm{~B}_{24}$ & 6900 & 170 & 85 & 0.535 & & & & & dis \\
\hline $\mathrm{B}_{19} \mathrm{E}_{58} \mathrm{~B}_{19}$ & 5300 & 130 & 65 & 0.553 & & & & & dis \\
\hline $\mathrm{B}_{46} \mathrm{E}_{99} \mathrm{~B}_{46}$ & 11000 & 273 & 136 & 0.637 & 109 & 121 & 119 & 123 & hex \\
\hline $\mathrm{B}_{37} \mathrm{E}_{77} \mathrm{~B}_{37}$ & 8700 & 217 & 108 & 0.645 & 91 & 74 & 69 & 74 & hex \\
\hline $\mathrm{B}_{49} \mathrm{E}_{63} \mathrm{~B}_{49}$ & 9800 & 248 & 124 & 0.746 & 96 & 56 & 54 & 57 & bcc \\
\hline
\end{tabular}

${ }^{a} r_{v}=m+1.89 n$ and $\phi_{B}=1.89 n /[m+1.89 n]$ (see ref 21 , Table 2 , for details), $r_{v}{ }^{*}=r_{v} / 2 .{ }^{b}$ Periodicity of the ordered melt at $70{ }^{\circ} \mathrm{C}$. Other samples melted directly to the disordered melt. ${ }^{\mathrm{C}} \mathrm{T}_{\mathrm{ODT}}=$ order-disorder transition temperature determined while heating the sample. Estimated error: $\pm 1{ }^{\circ} \mathrm{C}$ from SAXS and $\pm 2{ }^{\circ} \mathrm{C}$ from rheology. ${ }^{\mathrm{d}}$ lam = lamella; hex = hexagonal (cylinders); bcc $=$ body-centered cubic (spheres, QIm3̄m); dis = disordered. e Data for supercooled melt: $T_{\text {DOT }}$ determined while cooling the sample.

tuation corrections to $\left(\chi \mathrm{r}_{\mathrm{v}}\right)_{\mathrm{c}}$ scale in the familiar way, $\Delta$ $\sim r^{1 / 3}$, regardless of block architecture. ${ }^{7,17-19}$

In comparing results for the different copolymers considered in our work, it is assumed that $\chi$ has the same value for all architectures. As in earlier work, for example refs 8,9 , and 12 , this might be taken for granted. The matter has been addressed specifically by Adams et al., 10 who found that microphase separation in range of diblock and triblock poly(styrene)/poly(isoprene) block copolymers of constant composition, 13 wt \% poly(styrene), could be described by single $\chi(T)$ relation. Recently, Maurer et al. ${ }^{20}$ questioned the applicability of a single $\chi(T)$ relation based on comparison of values of $\chi$ derived from studies of phase separation in melts of binary polymer blends and diblock copolymers. Finding that $\chi$ differed between the two systems, they argued that this was a consequence of inaccuracy in the theory of the ODT in diblock copolymer melts and used a simple calculation to account for the polarization of a diblock copolymer prior to the ordering transition and to justify their argument. Ideally, $\chi$ should be determined from an equilibrium feature which experiment can measure precisely and which theory can predict accurately. ODT measurements satisfy the empirical requirement, but theoretically the ODT is difficult to model. However, it can be safely assumed that inaccuracies in theory are systematic across architectures and that if similar systems are compared, then these inaccuracies cancel. With respect to $\chi(T)$, the present comparison of the two different block copolymer architectures rests on this assumption, as does that of Adams et al. ${ }^{10}$

The mi crophase-separation behavior of melts of diblock copolymers of ethylene oxide and 1,2-butylene oxide $\left(E_{m} B_{n}\right)$ has been reported, ${ }^{21}$ and the experimental results have been compare ${ }^{21,22}$ with the phase diagram calculated using the exact self-consistent mean-field theory. ${ }^{23} \mathrm{H}$ ere $\mathrm{E}$ represents an oxyethylene unit, $\mathrm{OCH}_{2-}$ $\mathrm{CH}_{2}$, and $\mathrm{B}$ an oxybutylene unit, $\mathrm{OCH}_{2} \mathrm{CH}\left(\mathrm{CH}_{2} \mathrm{CH}_{3}\right)$. In this paper we report new results for 19 triblock copolymers of type $B_{n / 2} E_{m} B_{n / 2}$ and compare the results with those of corresponding $E_{m} B_{n}$ diblock copolymers.

\section{Experimental Section}

2.1. Synthesis and Characterization. Triblock copolymers were prepared by sequential anionic polymerization of ethylene oxide followed by 1,2-butylene oxide. Details of the methods have been published:21,22 for triblock copolymers the difunctional initiator was diethylene glycol. Characterization of the products was by gel permeation chromatography (for distribution width) and by ${ }^{13} \mathrm{C}$ NMR spectroscopy (for absolute values of number-average molar mass and overall composition, plus confirmation of block structure). Together the two techniques give a complete mol ecular description of the copolymers. A summary of the molecular characteristics of the copolymers is given in Table 1: i.e., the formulas in $B_{n / 2} E_{m} B_{n / 2}$ notation and the number-average molar mass $\left(M_{n}\right)$. All of the copolymers had narrow molar mass distributions: $\mathrm{M}_{\mathrm{w}} / \mathrm{M}_{\mathrm{n}} \leq 1.05$. Included in Table 1 are the volume fraction of the oxybutylene block in the liquid state at $70^{\circ} \mathrm{C}\left(\phi_{\mathrm{B}}\right)$ and the overall length of the copolymer molecule in segments $\left(r_{v}\right)$, taking the segment reference volume to be that of an E unit. Specific volumes were taken from Mai et al. ${ }^{24}$ The listing is in ascending order of $\phi_{\mathrm{B}}$. The chain lengths are listed normally as $r_{v}$ and, in keeping with the discussion in the Introduction, as the half-length of a triblock copolymer $r_{v}{ }^{*}=r_{v} / 2$. For a diblock copolymer $r_{v}{ }^{*}=$ $r_{\mathrm{v}}$.

2.2. Small-Angle X-ray Scattering. SAXS measurements were made on beamline 8.2 of the SRS at the CCLRC Daresbury Laboratory, Warrington, UK. The method used has been described in detail previously. ${ }^{25}$ The camera was equipped with a multiwire quadrant detector located $3.5 \mathrm{~m}$ from the sample position. Samples were placed in a TA Instruments DSC pan containing a $0.75 \mathrm{~mm}$ brass spacer ring and fitted with windows made from $25 \mu \mathrm{m}$ thick mica. The loaded pans were placed in the cell of a Linkam DSC of single-pan design. A complete description of the DSC and the sample pans, including calibration of the temperature scale, can be found elsewhere. ${ }^{26,27}$ The temperature program was as follows: heat from room temperature to $30^{\circ} \mathrm{C}$ above the temperature of the ODT (TODT $+30{ }^{\circ} \mathrm{C}$ ) at $10{ }^{\circ} \mathrm{C} \mathrm{min}^{-1}$, hold at maximum temperature for $1 \mathrm{~min}$, and cool at $10^{\circ} \mathrm{C} \mathrm{min}^{-1}$ to $10^{\circ} \mathrm{C}$. In some cases temperature ramps of 2 and $5{ }^{\circ} \mathrm{C} \mathrm{min}-1$ were also applied to check for heating rate effects. The data acquisition system ${ }^{27}$ had a time frame generator which collected the data in $6 \mathrm{~s}$ frames separated by a wait time of $10 \mu \mathrm{s}$. The scattering pattern from an oriented specimen of wet collagen (rat tail tendon) was used for calibration. The experimental data were corrected for background scattering (subtraction of the scattering from the camera, hot stage, and an empty cell), sample 
Table 2. Molecular Characteristics and Microphase-Separation Behavior of $E_{m} B_{n}$ Copolymers from Ref 21

\begin{tabular}{crrrrcc}
\hline copolymer & $\mathrm{M}_{\mathrm{n}} / \mathrm{g} \mathrm{mol}^{-1}$ & $\mathrm{r}_{\mathrm{v}}{ }^{\mathrm{a}}$ & \multicolumn{1}{c}{$\phi_{\mathrm{B}}{ }^{\mathrm{a}}$} & $\begin{array}{c}\mathrm{d} / \AA^{\mathrm{b}} \\
\left(70{ }^{\circ} \mathrm{C}\right)\end{array}$ & $\begin{array}{c}\mathrm{T}_{\mathrm{ODT}} /{ }^{\circ} \mathrm{C}^{\mathrm{c}} \\
\mathrm{SAXS}\end{array}$ \\
\hline $\mathrm{E}_{43} \mathrm{~B}_{23}$ & 3400 & 86 & 0.503 & & \\
$\mathrm{E}_{85} \mathrm{~B}_{45}$ & 7000 & 170 & 0.500 & 119 & 140 \\
$\mathrm{E}_{100} \mathrm{~B}_{51}$ & 8100 & 196 & 0.491 & 131 & 165 \\
$\mathrm{E}_{76} \mathrm{~B}_{38}$ & 6100 & 148 & 0.486 & 109 & 114 \\
$\mathrm{E}_{96} \mathrm{~B}_{47}$ & 7600 & 185 & 0.481 & 127 & 163 \\
$\mathrm{E}_{114} \mathrm{~B}_{56}$ & 9000 & 220 & 0.481 & 146 & 210 \\
$\mathrm{E}_{155} \mathrm{~B}_{76}$ & 12300 & 299 & 0.481 & 174 & 270 \\
$\mathrm{E}_{56} \mathrm{~B}_{27}$ & 4400 & 107 & 0.477 & $89\left(50{ }^{\circ} \mathrm{C}\right)^{\mathrm{d}}$ & \\
$\mathrm{E}_{60} \mathrm{~B}_{29}$ & 4700 & 115 & 0.477 & $93\left(50^{\circ} \mathrm{C}\right)$ & 60
\end{tabular}

${ }^{a} r_{v}=m+1.89 n$ and $\phi_{B}=1.89 n /[m+1.89 n]$ (see ref 21 , Table 2 , for details), $r_{v}{ }^{*}=r_{v} / 2$. ${ }^{b}$ Periodicity of the ordered melt at 70 ${ }^{\circ} \mathrm{C}$. Other samples melted directly to the disordered melt. ${ }^{\mathrm{C}} \mathrm{T}$ ODT $=$ order-disorder transition temperature determined while heating the sample. Estimated error: $\pm 1{ }^{\circ} \mathrm{C}$ from SAXS and $\pm 2{ }^{\circ} \mathrm{C}$ from rheology. ${ }^{d}$ Data for supercool ed melt: $\mathrm{T}_{\mathrm{DOT}}$ determined while cooling the sample.

thickness, and transmission and for any departure from positional linearity of the detector.$^{25}$ Results are presented in terms of the wave vector $q=(4 \pi / \lambda) \sin (\theta / 2)$, where the wavelength $\lambda=1.54 \AA$ and $\theta$ is the scattering angle.

Because the SAXS patterns of some samples showed only one or two peaks, the structures of their ordered phases could be difficult to deduce. One problem was that for samples with $\phi_{\mathrm{B}} \approx 0.5$ the second-order peak from the lamellar structure coincided with the first minimum in the form factor. Accordingly, the same beamline equipped with a multiwire 2D detector located $2 \mathrm{~m}$ from the sample was used to determine the SAXS 2D patterns of several oriented samples in order to confirm their structures. The samples were sheared manually in custom-made cells, each consisting of a brass plate with machined side grooves to al low movement of a parallel slider. The sample thickness was about $1 \mathrm{~mm}$, and the beam passed through a hole of $6 \mathrm{~mm}$ diameter which was covered with Kapton film. The plate was attached to a large-thermal-mass holder and heated on a hot plate, the polymer temperature being monitored by a thermocouple. The copolymer melts were sheared at $60-80{ }^{\circ} \mathrm{C}$ at frequency $\mathrm{f} \approx 1 \mathrm{~Hz}$ and strain amplitude $A \approx 200 \%$ for $5 \mathrm{~min}$ or more before the SAXS pattern was recorded.

2.3. Rheology. Rheological measurements were made with either a Rheometrics RDA-II rheometer or a DSR-5000 rheometer. Films of uniform thickness (ca. $2 \mathrm{~mm}$ ), prepared by compressing a sample under vacuum at $60^{\circ} \mathrm{C}$ for 1 day, were placed in a shear-sandwich fixture for examination (gap $=1.8$ $\mathrm{mm}$ ). In the isochronal experiment, the furnace was heated at $1{ }^{\circ} \mathrm{C} \mathrm{min}-1$ from 60 to $20^{\circ} \mathrm{C}$ above the temperature of the ODT of the sample, with the sample tested at $30 \mathrm{~s}$ intervals at frequency $\omega=1 \mathrm{rad} \mathrm{s}^{-1}$ and $\mathrm{A}=1 \%$. The furnace was flushed with dry nitrogen throughout the experiment.

\section{Results and Discussion}

The microphase-separation behavior of diblock copolymers of ethylene oxide and 1,2-butylene oxide $\left(E_{m} B_{n}\right)$ has been reported in detail previously. ${ }^{21}$ For convenience of discussion, the results obtained for those diblock copolymers with $\phi_{\mathrm{B}} \approx 0.5$ which microphaseseparated are reproduced in Table 2. Our present systematic studies are concentrated on the effect of architecture on microphase-separation behavior. In this paper we present the results obtained for $B_{n / 2} E_{m} B_{n / 2}$ triblock copolymers and compare them with those of corresponding $E_{m} B_{n}$ diblock copolymers. To complete the picture, we hope in the near future to report results for the copolymers with the inverse triblock architecture, $\mathrm{E}_{\mathrm{m} / 2} \mathrm{~B}_{n} \mathrm{E}_{\mathrm{m} / 2{ }^{28}}$

3.1. Order-Disorder Transition Temperature. SAXS. All the copolymers were examined by 1D SAXS.

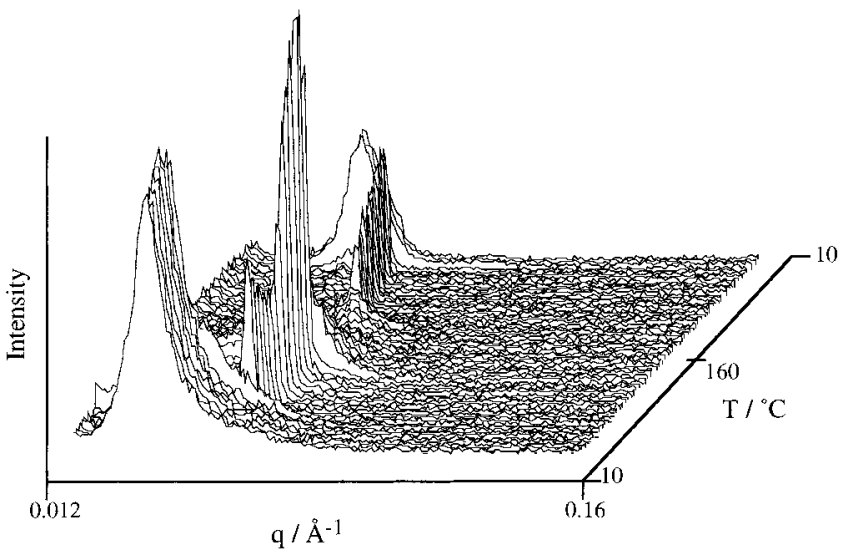

Figure 1. Three-dimensional relief diagram of time-resolved SAXS obtained with a time resolution of $6 \mathrm{~s}$ while heating and cooling copolymer $\mathrm{B}_{46} \mathrm{E}_{99} \mathrm{~B}_{46}$. The plot shows intensity versus scattering vector, $\mathrm{q}$, versus temperature, $\mathrm{T}$. The thermal cycle was $10{ }^{\circ} \mathrm{C} \rightarrow 160{ }^{\circ} \mathrm{C} \rightarrow 10{ }^{\circ} \mathrm{C}$ at a ramp rate of $10^{\circ} \mathrm{C}$ $\min ^{-1}$.

Results obtained for copolymer $\mathrm{B}_{46} \mathrm{E}_{99} \mathrm{~B}_{46}$ are illustrated in Figure 1, which shows a three-dimensional relief diagram of time-resolved SAXS data obtained during heating and cooling the copolymer. The behavior is similar to that of $E_{m} B_{n}$ diblock copolymers. ${ }^{21}$ The SAXS pattern at low temperature is consistent with a semicrystalline lamellar phase. At intermediate temperature $\left(54 \leq \mathrm{T} \leq 124^{\circ} \mathrm{C}\right)$, the sharp narrow peak indicates an ordered melt with a totally different periodicity from the semi crystall ine structure. The broad scattering peak at higher temperatures $\left(T>124{ }^{\circ} \mathrm{C}\right)$ indicates a disordered melt with composition fluctuations. The phase sequence is reversed on cooling. Such heating and cooling experiments were used to locate the ODT, as described in detail previously. 22 The temperature at the ODT was defined not only from the step change in the peak maximum intensity but also from discontinuous changes in peak width and peak shape (see Figure 1). An ODT was observed for 11 of the copolymers, and a disorderto-order transition (DOT) was observed for a twelfth in its supercooled melt. Values of the transition temperatures (TODT and $\mathrm{T}_{\mathrm{DOT}}$ ) from SAXS, corrected for thermal lag, are listed in Table 1.

Rheology. Figure 2 shows plots of dynamic storage moduli $\mathrm{G}^{\prime}\left(\omega=1 \mathrm{rad} \mathrm{s}^{-1}\right)$ obtained as a function of temperature during a heating experiment on copolymers $\mathrm{B}_{29} \mathrm{E}_{111} \mathrm{~B}_{29}, \mathrm{~B}_{37} \mathrm{E}_{77} \mathrm{~B}_{37}$, and $\mathrm{B}_{49} \mathrm{E}_{63} \mathrm{~B}_{49}$, which microphaseseparated into lam, hex, and bcc structures, respectively. The temperature at which there was a distinct drop in $\mathrm{G}^{\prime}$ was defined as $\mathrm{T}_{\mathrm{ODT}}$. Values of T ODT were obtained in this way for seven of the copolymers; see Table 1.

Comparison with Diblock Copol ymers. Figure 3 shows values of $\mathrm{T}_{\mathrm{ODT}}$ for the triblock (present work) and the diblock (previous work ${ }^{21}$ ) copol ymers with $\phi_{\mathrm{B}} \approx 0.5$. The curves in Figure 3 are added to guide the eye through the data points. Compared at identical $r_{v}$, the values of TODT are some $100{ }^{\circ} \mathrm{C}$ lower than those of $E_{m} B_{n}$ diblock copolymers: compared at identical $r_{v}{ }^{*}$ they are some $30{ }^{\circ} \mathrm{C}$ higher. These results are as expected: see the Introduction.

3.2. Values of $\chi$. Values of $\chi$ were calculated from the values of $\mathrm{T}_{\mathrm{ODT}}$ found for the triblock copolymers with $\phi_{\mathrm{B}} \approx 0.5$ using either a mean-field value of $\chi \mathrm{r}_{\mathrm{v}}=18$ or, following Fredrickson and Helfand, ${ }^{29}$ a fluctuationcorrected value of $\chi r_{v}=18+90 \bar{N}^{-1 / 3}$, where $\bar{N}=r_{v} b^{6} \rho^{2}$, and the fluctuation coefficient of 90 is estimated by 


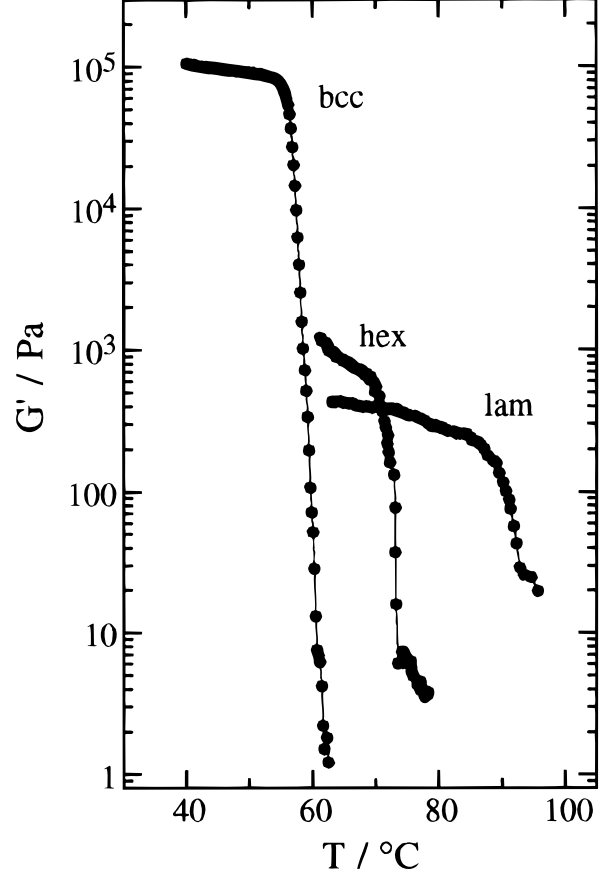

Figure 2. Temperature dependence of the low-frequency ( $\omega$ $\left.\ll \omega_{c}\right)$ dynamic storage moduli $\mathrm{G}^{\prime}\left(\omega=1 \mathrm{rad} \mathrm{s}^{-1}\right.$ and strain amplitude $A=1 \%$ ) for triblock copol ymer mel ts with different structures: $\mathrm{B}_{49} \mathrm{E}_{63} \mathrm{~B}_{49}$ (bcc), $\mathrm{B}_{37} \mathrm{E}_{77} \mathrm{~B}_{37}$ (hex), and $\mathrm{B}_{29} \mathrm{E}_{111} \mathrm{~B}_{29}$ (lam).

comparing our mean-field phase diagram to the fluctuation phase diagram in ref 7 . As previously, ${ }^{21}$ the approximate values of the statistical length $b \approx 5.3 \times$ $10^{-10} \mathrm{~m}$ and the number density $\rho \approx 1.4 \times 10^{28} \mathrm{~m}^{-3}$ were used in the calculation of $\overline{\mathrm{N}}$. The values of $\chi$ are plotted in Figure 4, where comparison is made with those obtained $^{21}$ for diblock $\mathrm{E}_{\mathrm{m}} \mathrm{B}_{\mathrm{n}}$ copolymers with $\phi_{\mathrm{B}} \approx 0.5$. Within experimental error (approximately indicated by the size of the symbols) the new values of $\chi$ for the triblock copolymers are fully consistent with the old values of $\chi$ for the diblock copolymers. The best straight lines (least squares) through all the data points are

$$
\chi=52.6 / \mathrm{T}-0.0632
$$

for the mean-field calculation, and

$$
\chi=85.4 / \mathrm{T}-0.113
$$

for the fluctuation calculation. As shown by Bates and co-workers, ${ }^{20,30}$ the $\mathrm{F}$ redrickson and $\mathrm{Hel}$ fand fluctuation correction ${ }^{29}$ for diblock copolymers (and, presumably, the related expression for triblock copolymers quoted above) can be usefully applied to melts of copolymers with $\overline{\mathrm{N}}$ as low as 3000 . Recent work ${ }^{31}$ indicates that this conclusion extends down to copolymers with $\bar{N} \approx 500$.

3.3. Microphase Structure. The information from 1D SAXS patterns (e.g., single frames from Figure 1), 2D SAXS patterns from orientated samples, and $\mathrm{G}^{\prime}(T)$ curves from rheology was used to determine the microphase structures of the samples.

Figure 5a shows a 2D SAXS plot obtained for an oriented sample of copolymer $\mathrm{B}_{46} \mathrm{E}_{99} \mathrm{~B}_{46}\left(\phi_{\mathrm{B}}=0.64\right)$. Figure $5 \mathrm{~b}$ shows a 1D SAXS plot obtained by integrating over the arcs on the equator. The degree of orientation achieved was low, reflecting the rather low strain amplitude used. Nevertheless, concentration of intensity on the equator of the SAXS pattern enabled clear recognition of reflections at $q / q^{*}=1: \sqrt{ } 4: \sqrt{ } 7$ (where $q^{*}$

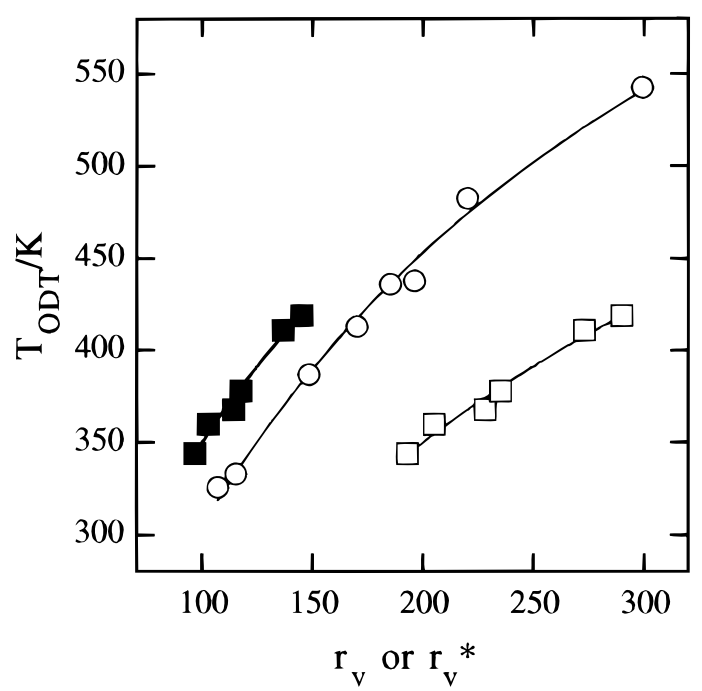

Figure 3. Values of T ODT for triblock $(\square, \square)$ and diblock $(\bigcirc)$ copolymers plotted against chain length $r_{v}$ (open symbols) and $r_{\mathrm{v}}{ }^{*}=r_{\mathrm{v}} / 2$ (closed symbols).

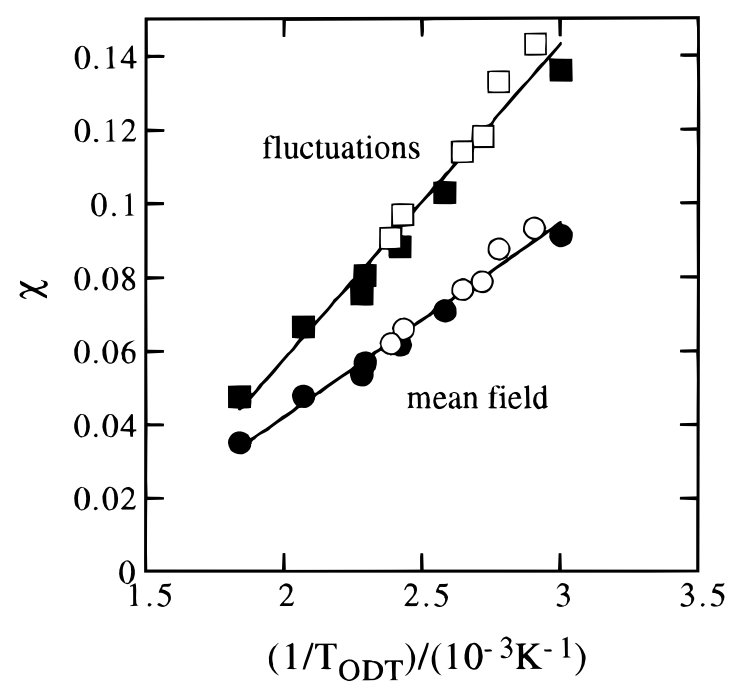

Figure 4. Values of the Flory-Huggins interaction parameter $\chi$ versus reciprocal order-disorder transition temperature ( $\mathrm{T}_{\text {ODT }}$ ) calculated for triblock copolymers (unfilled symbols) and diblock copolymers (filled symbols) with $\phi_{\mathrm{B}} \approx 0.5$. As indicated, the calculations assume either a mean field or a fluctuating melt (see text for details). In each case the line is the leastsquares fit to all the data points.

is the q value for the intense first-order reflection), thus allowing assignment to a hex phase (hexagonally packed cylinders). Other copolymers were oriented to a similar extent, and third-order reflections were observed.

Under identical conditions (i.e., gap, temperature, frequency, and strain amplitude), distinct and reproducible values of G' were found for samples with different microphase structures. The curves in Figure 2 are typical: for those samples values of $\mathrm{G}^{\prime}$ for structured phased at temperatures near $60^{\circ} \mathrm{C}$ are approximately $80 \mathrm{kPa}$ (bcc), $1 \mathrm{kPa}$ (hex), and $0.5 \mathrm{kPa}$ (lam). The last two values are a little lower than those reported by others for lam and hex phases, ${ }^{12-14}$ possibly reflecting the short chain lengths of our copolymers.

The structures defined using the combination of techniques are listed in Table 1.

3.4. Phase Diagram. Using eq 1 , the results listed in Table 1 are plotted in Figure $6 a$ as $\chi \mathrm{r}_{\mathrm{v}}{ }^{*}$ against $\phi_{\mathrm{B}}$. The microphase-separation boundary predicted $^{5}$ for 

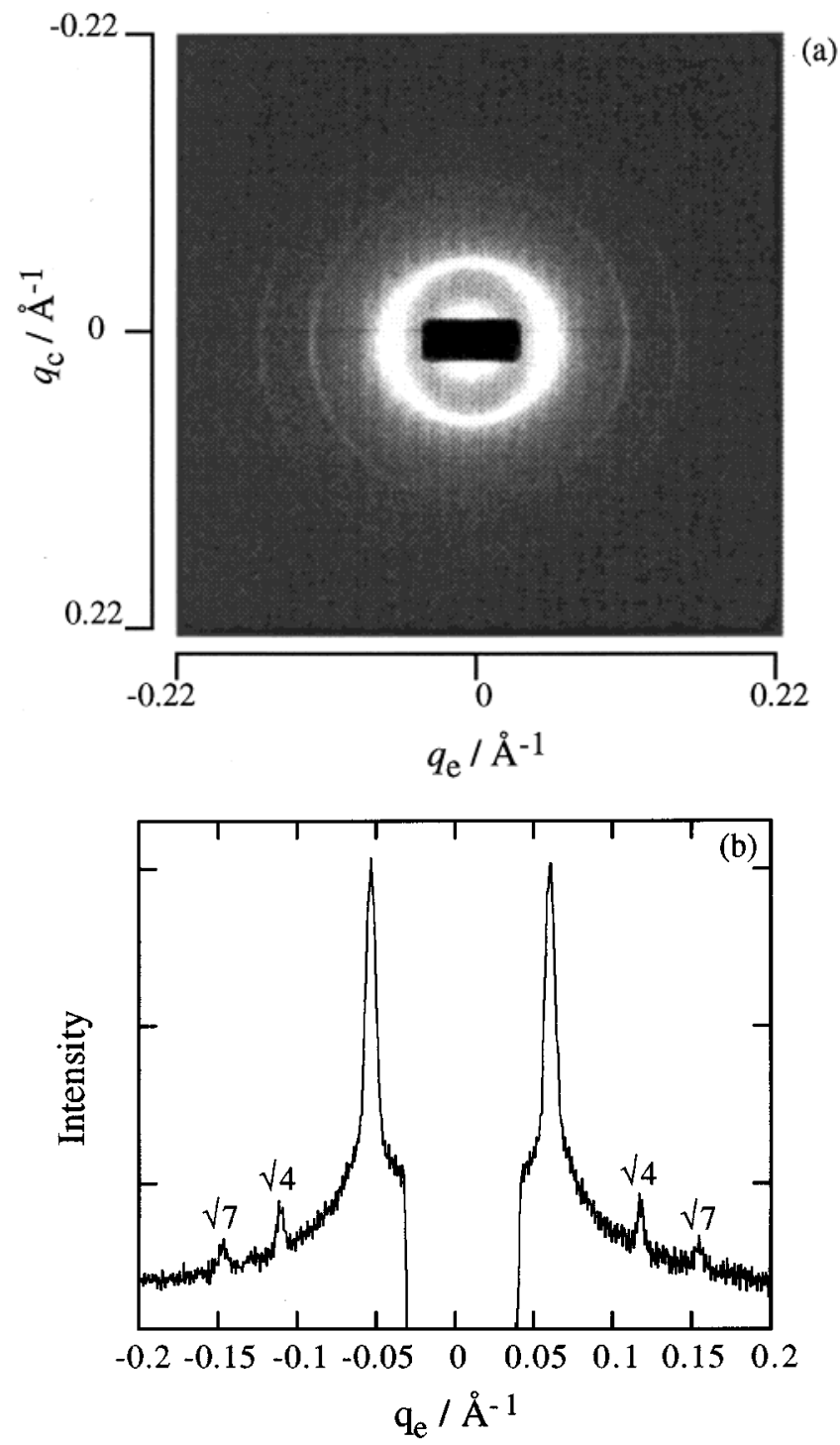

Figure 5. (a) 2D SAXS plot of the oriented samples $B_{46} E_{99} B_{46}$. (b) ID SAXS plot obtained by integrating over the arcs on the equator.

triblock copolymers by self-consistent mean-field theory is also shown. Plotted in this way the predicted critical value of $\chi r_{v}{ }^{*}$ for triblock copolymers is $\left(\chi r_{v}{ }^{*}\right)_{c}=9$, which allows ready comparison with the microphase-separation boundary predicted for diblock copolymers. Both calculated curves take account of the effect of the difference in statistical length between the two segments by including the asymmetry factor, $\epsilon=\left(v_{E} b_{B}{ }^{2}\right)$ $\left.v_{B} b_{E}{ }^{2}\right)=0.6$, where $v_{E}, v_{B}, b_{E}$, and $b_{B}$ represent the volumes and statistical lengths of the $E$ and $B$ units. In fact, the actual value for the E/B system is $0.65,{ }^{21,22}$ but calculations indicate that such a small difference is quantitatively unimportant. ${ }^{5}$

It is seen that the calculated phase diagram is skewed toward the $\phi_{\mathrm{B}}=1$ axis, as predicted by Mayes and Olvera de la Cruz, ${ }^{6}$ and that the experimental points are in good agreement with theory. This comparison of experiment with theory is consistent, since the calculation and the experimental values of $\chi(\mathrm{T})$ used are both based on the mean-field approximation, and any errors are compensated. As described in section 3.2, we are aware of the possibility of taking account of concentration fluctuations in the disordered phase and have carried this through in treating our data for diblock
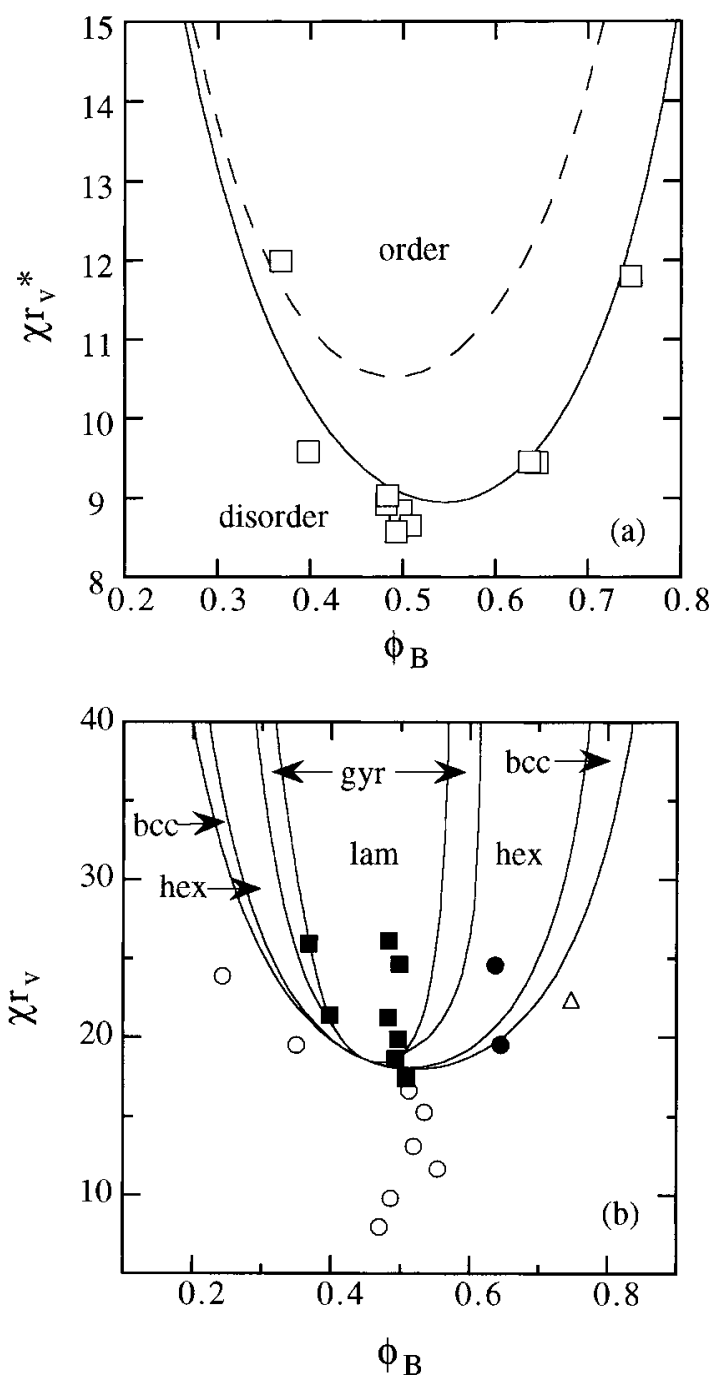

Figure 6. (a) Phase diagram $\left(\chi r_{v} *\right.$ versus $\left.\phi_{B}\right)$ for $B_{n / 2} E_{m} B_{n / 2}$ copolymers constructed using $\chi$ given by eq 1 . The squares denote experimental order-disorder transitions (ODT). The full curve is the microphase-separation boundary predicted for triblock copolymers, and the dashed curve is the corresponding curve predicted for diblock copolymers. Both curves were calculated for the E/B system using the full self-consistent mean-field theory ${ }^{23}$ with asymmetry factor $\epsilon=0.6$. Chain lengths: $r_{v}{ }^{*}=r_{v}$ for the diblock copolymers, $r_{v}^{*}=r_{v} / 2$ for the triblock copolymers. (b) The positions of the $B_{n / 2} E_{m} B_{n / 2}$ triblock copolymers, calculated for $\chi=0.0901$ corresponding to a melt temperature of $70^{\circ} \mathrm{C}$, on the phase diagram calculated using the full self-consistent mean-field theory: $:, 23(\mathrm{O})$ disordered, i.e.,

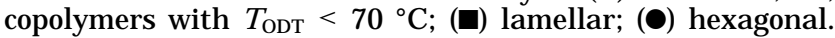
The symbol $\Delta$ indicates the result for copolymer $\mathrm{B}_{49} \mathrm{E}_{63} \mathrm{~B}_{49}$ which has a bcc melt structure below $55^{\circ} \mathrm{C}$.

copolymers. ${ }^{21}$ However, secure progress in that area must rest on values of $\chi(\mathrm{T})$ from experiments that are independent of TODT. At present these are not available.

A full phase diagram showing the individual microphases has been calculated for symmetrical triblock copolymers using the exact self-consistent mean-field theory ${ }^{5}$ (see Figure 6b). As for Figure 6a, the asymmetry factor $\epsilon=0.6$. Both the triblock copol ymer architecture and the asymmetry factor lead to the microphases being asymmetrically situated about $\phi_{\mathrm{B}}=0.5$. The positions of the $B_{n / 2} E_{m} B_{n / 2}$ triblock copolymers on this phase diagram were calculated using the value of $\chi=0.0901$ corresponding, by eq 1 , to a melt temperature of $70^{\circ} \mathrm{C}$. As noted above, the use of mean-field theory for both calculated phase diagram and experimental data points 
allows compensation of error. Even so, as can be seen in Figure 6b, the observed structures do not agree exactly with the theoretical predictions: the experimental points display a larger asymmetry in the phase diagram than that predicted by theory. Strictly, the SCF theory applies to copolymers that are many times longer than their persistence length, and as a consequence, the phase boundaries are unlikely to be accurate for short copolymers. The effect of their limited flexibility has been explored theoretically but only applied to the lamellar phase. ${ }^{32}$

As is obvious from Figure $6 \mathrm{~b}$, the information available at present for BEB copol ymers remains sparse. For example, we have not yet reported a BEB-copolymer melt with the bicontinuous gyroid structure, although this structure is known for other triblock copolymers. 33,34 However, whatever the shortcomings of Figure $6 b$, it is the most complete to be reported for a triblock copolymer at the present time. We hope to add to it as time permits.

3.5. Domain Spacing. The domain spacing in the ordered melts was cal culated from the one-dimensional SAXS patterns as $d=2 \pi / q^{*}$; see Table 1 . Results for triblock copolymers with $\phi_{\mathrm{B}} \approx 0.5$ and results for diblock $\mathrm{E} / \mathrm{B}$ copolymers (also $\phi_{\mathrm{B}} \approx 0.5$ ) are compared in Figure 7a. The d-spacings for the diblock copolymers were measured mainly with the samples at $70{ }^{\circ} \mathrm{C}$ (see Table 2), and those for the triblocks were all measured at 70 ${ }^{\circ} \mathrm{C}$. Compared at the same $r_{v}$, the $d$-spacings for the triblock copolymers are much lower than those of the diblock copolymers (not shown in Figure 7a, see Tables 1 and 2). Compared at the same value of $r_{v}{ }^{*}$, the data points for the triblock copolymers lie slightly above those for the diblock copolymers; see Figure 7a. For the six triblock samples, the average ratio $\mathrm{d}_{\mathrm{tri}} / \mathrm{d}_{\mathrm{di}} \approx 1.10$; i.e., on average the triblock copolymer chains are $10 \%$ more stretched than those of the diblock copolymers. In Figure $7 \mathrm{~b}$ the experimental data for triblock copolymers with $\phi_{\mathrm{B}} \approx 0.5$ are compared with values of $\mathrm{d}_{\mathrm{tri}} / \mathrm{d}_{\mathrm{di}}$ calculated using self-consistent mean-field theory. ${ }^{5}$ Within the experimental scatter the agreement is very satisfactory.

Matsushita et al. have reported values of the $d$ spacing for triblock and diblock copolymers of poly(2vinylpyridine) and poly(styrene). ${ }^{35}$ Compared at the same value of $r_{v}{ }^{*}$ (our notation, i.e., taking the halflength for the triblock copolymer) values of $d$ were essentially the same within experimental error. This result does not contradict ours, since the chain lengths of Matsushita's triblock copolymers were long, more than 1000-5000 segments based on our reference volume, and so well into the strong segregation region of the phase diagram and well outside the range of our results. The prediction is that the ratio $d_{\text {tri }} / d_{d i}$ falls toward unity with increase in chain length (see Figure 7b), ${ }^{5}$ and Matsushita's copolymers may be effectively at the Helfand-Wasserman limit. ${ }^{36}$

Finally, it is important to stress that we have used the observed and calculated ratio $d_{t r i} / d_{d i}$ in discussing the results, rather than the $d$ spacings themselves. Given the low molar masses of the copolymers, the SCFT predictions cannot be very accurate. Even with fluctuations taken into account, it is found that observed and calculated values differ by some 10-15\%. However, since the discrepancy applies systematically to diblock and triblock copolymers alike, the ratio should be accurate.
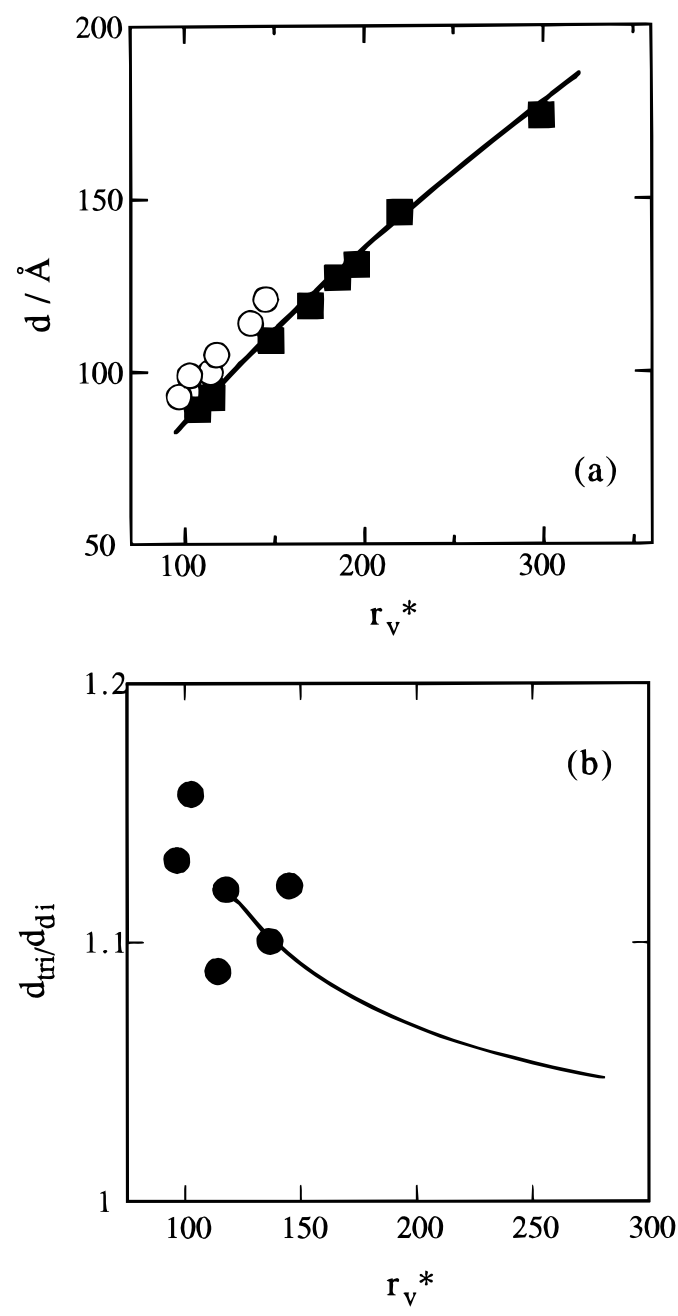

Figure 7. (a) Domain spacings (d-spacings) for ( $\square$ ) triblock and $(O)$ diblock copolymers with $\phi_{\mathrm{B}} \approx 0.5$ plotted against chain length $r_{v}{ }^{*}$. The curve fitted to the data points for the diblock copolymers is $d_{d i}=3.9\left(r_{v}{ }^{*}\right)^{0.67}$. Chain lengths: $r_{v}{ }^{*}=r_{v}$ for the diblock copol ymers, $r_{v}{ }^{*}=r_{v} / 2$ for the triblock copolymers. (b) Experimental values of $d_{t r i} / d_{d i}$ compared with those calculated using self-consistent mean-field theory. ${ }^{5}$

\section{Conclusions}

The work on triblock oxybutylene/oxyethylene/oxybutylene copolymers reported in this paper, together with previous work on corresponding diblock copolymers, permits a number of conclusions.

(i) Values and temperature dependencies of $\chi$ obtained from analysis of ODT temperatures are the same for diblock and triblock copolymers.

(ii) The asymmetry in the microphase-separation boundary predicted by theory is confirmed.

(iii) The positions of the lamellar and hexagonal (cylindrical) regions of the phase diagram found by experiment are more asymmetric in the phase diagram than is predicted by mean-field theory.

(iv) The triblock copolymers investigated are 10\% more stretched in the lamellar phase than their corre sponding di block copolymers, in quantitative agreement with theory.

Acknowledgment. A research studentships was provided by the Engineering and Physical Research Council (EPSRC, UK) for S.C.T. The Thai Government provided financial support for W.M. and C.C. EPSRC supported the project through Grants GR/L22645 and 
GR/L 22621. We also thank Mr. K. Nixon and Mr. P. A. Mackenzie for their practical help.

\section{References and Notes}

(1) Hamley, I. W. The Physics of Block Copolymers; Oxford University Press: Oxford, 1998.

(2) The change in enthal py is twice as much for the BEB triblock because twice as many E segments would have to be pulled into the B domain. The change in entropy is al so about twice as much for the triblock because each half is stretched similarly to the chain of a diblock; see ref 3.

(3) Matsen, M. W.; Schick, M. Macromolecules 1994, 27, 187.

(4) Matsen, M. W. J . Chem. Phys. 1995, 102, 3884.

(5) Matsen, M. W.; Thompson, R. B. J . Chem. Phys. 1999, 111, 7139.

(6) Mayes, A. M.; Olvera de la Cruz, M. J . Chem. Phys. 1989, $91,7228$.

(7) Mayes, A. M.; Olvera de la Cruz, M. J . Chem. Phys. 1991 95, 4670.

(8) Koberstein, J. T.; Russell, T. P.; Walsh, D. J .; Pottick, L. Macromol ecules 1990, 23, 877.

(9) Gehlsen, M. D.; Almdal, K.; Bates, F. S. Macromol ecules 1992 25, 939.

(10) Adams, J . L.; Graessley, W. W.; Register, R. A. Macromolecules 1994, 27, 6026.

(11) Mckay, K. W.; Gros, W. A.; Diehl, C. F. J . Appl. Polym. Sci. 1995, 56, 947.

(12) Riise, B. L.; Fredrickson, G. H.; Larson, R. G.; Pearson, D. S. Macromolecules 1995, 28, 7653.

(13) Nakatani, A. I.; Morrison, F. A.; Douglas, J . F.; Mays, J . W.; J ackson, C. L.; Muthukumar, M.; Han, C. C. J . Chem. Phys. 1996, 104, 1589.

(14) Ryu, C. Y.; Lee, M. S.; Hajduk, D. A.; Lodge, T. P. J . Polym. Sci., Part B: Polym. Phys. 1997, 35, 2811.

(15) Kim, J. K.; Lee, H. H.; Gu, Q.J .; Chang, T.; J eong, Y. H. Macromol ecules 1998, 31, 4045.

(16) Leibler, L. Macromolecules 1980, 13, 1602.

(17) Fredrickson, G. H.; Helfand, E. J . Chem. Phys. 1987, 87, 697.

(18) Bates, F. S.; Rosedale, J. H.; Fredrickson, G. H. Phys. Rev. Lett. 1988, 19, 2229.

(19) Hamley, I. W.; Podneks, V. E. Macromolecules 1997, 30, 3701.
(20) Maurer, W. M.; Bates, F. S.; Lodge, T. P.; Almdal, K.; Mortensen, K.; Fredrickson, G. H. J . Chem. Phys. 1998, 108, 2989.

(21) Mai, S.-M.; Fairclough, J . P. A.; Terrill, N. J .; Turner, S. C.; Hamley, I. W.; Matsen, M. W.; Ryan, A. J .; Booth, C. Macromolecules 1998, 31, 8110.

(22) Mai, S.-M.; Fairclough, J. P. A.; Hamley, I. W.; Matsen, M. W.; Denny, R. C.; Liao, B.-X.; Booth, C.; Ryan, A. J . Macromolecules 1996, 29, 6212.

(23) Matsen, M. W.; Bates, F. S. Macromolecules 1996, 29, 1092.

(24) Mai, S.-M.; Booth, C.; Nace, V. M. Eur. Polym. J . 1997, 33, 991.

(25) See, for example: Ryan, A. J .; Bras, W.; Mant, G. R.; Derbyshire, G. E. Polymer 1994, 35, 4537 and references therein.

(26) Ryan, A. J . J . Therm. Anal. 1993, 40, 887.

(27) Bras, W.; Derbyshire, G. E.; Clarke, S.; Devine, A.; Komanschek, B. U.; Cooke, J .; Ryan, A. J . J . Appl. Crystallogr. 1995, $28,26$.

(28) Mai, S.-M.; Chaibundit, C.; Turner, S. C.; Mingvanish, W.; Fairclough, J . P. A.; Heatley, F.; Matsen, M. W.; Ryan, A. J .; Booth, C., to be published.

(29) Fredrickson, G. H.; Helfand, E.J . Chem. Phys. 1987, 87, 697.

(30) Rosedale, J. H.; Bates, F. S.; Almdal, K.; Mortensen, K.; Wignall, G. D. Macromolecules 1995, 28, 1429.

(31) Fairclough, J. P. A.; Ryan, A. J .; Turner, S.; Hamley, I. W.; Mai, S.-M.; Booth, C.; Denny, R. C. Phys. Chem. Chem. Phys. 1999, 1, 2093

(32) Matsen, M. W. J . Chem. Phys. 1996, 104, 7758

(33) Laurer, J . H.; Hajduk, D. A.; Fung, J . C.; Sedat, J . W.; Smith, S. D.; Gruner, S. M.; Agard, D. A.; Spontak, R. J . Macromolecules 1997, 30, 3938.

(34) Avgeropoulos, A.; Dair, B. J .; Hadjichristidis, N.; Thomas, E. L. Macromol ecules 1997, 30, 5634.

(35) Matsushita, Y.; Nomura, M.; Watanabe, J .; Mogi, Y.; Noda, I.; I mai, M. Macromol ecules 1995, 28, 6007. Matsushita, Y.; Mori, K.; Saguchi, R.; Nakao, Y.; Noda, I.; Nagasawa, M. Macromolecules 1990, 23, 4313.

(36) Helfand, E.; Wasserman, Z. R. Macromol ecules 1976, 9, 879. MA000154Z 